ROSANE DE ALBUQUERQUE DOS SANTOS ABREU

A Internet na Prática Docente: Novos Desafios e Conflitos para os Educadores.

TESE DE DOUTORADO

DEPARTAMENTO DE PSICOLOGIA Programa de Pós-Graduação em Economia novembro de 2003 


\section{A INTERNET NA PRÁTICA DOCENTE: NOVOS DESAFIOS E CONFLITOS PARA OS EDUCADORES.}

Tese apresentada ao Departamento de Psicologia da PUC-Rio como parte dos requisitos para obtenção do título de Doutor em Psicologia.

Orientadora: Profa Ana Maria Nicolaci-da-Costa

Rio de Janeiro, 07 de novembro de 2003 


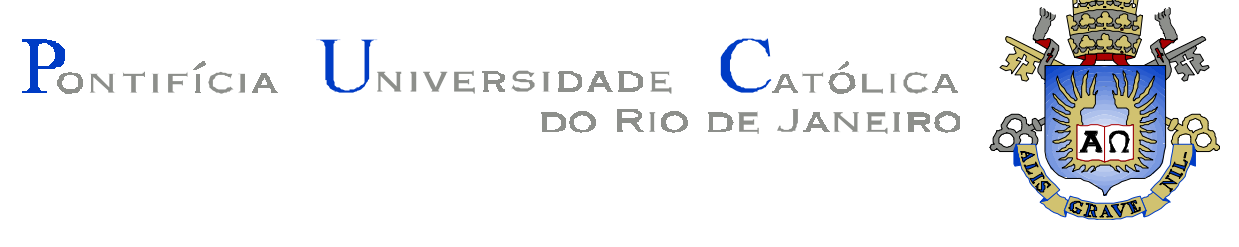

Rosane de Albuquerque dos Santos Abreu

\section{"A Internet na prática docente: novos desafios e conflitos para os educadores"}

Tese apresentada como requisito parcial para obtenção do grau de Doutor pelo Programa de Pós-Graduação em Psicologia Clínica do Departamento de Psicologia do Centro de Teologia e Ciências Humanas da PUC-Rio. Aprovada pela Comissão Examinadora abaixo assinada.

Profa. Ana Maria Nicolaci-da-Costa

Orientadora

Departamento de Psicologia - PUC-Rio

Prof $^{a}$. Maria Lucia Rocha Coutinho Instituto de Psicologia - UERJ

Profa $^{a}$. Maria Luiza M. Bastos Oswald Departamento de Educação - PUC-Rio

Profa . Zélia Maria Mendes Biasoli-Alves Departamento de Psicologia e Educação - USP/SP

Profa. Solange Jobim e Souza Departamento de Psicologia - PUC-Rio

Prof. Jürgen Heye

Coordenador Setorial de Pós-Graduação e Pesquisa do Centro de Teologia e Ciências Humanas - PUC-Rio 
Todos os direitos reservados. É proibida a reprodução total ou parcial do trabalho sem autorização do autor, do orientador e da universidade.

\section{Rosane de Albuquerque dos Santos Abreu}

A autora graduou-se em Pedagogia pela Universidade do Estado do Rio de Janeiro - UERJ, em 1976. Em 1990, defendeu dissertação de mestrado no Departamento de Educação da PUC/RJ, a qual foi indicada para publicação. Foi professora (auxiliar de ensino) do CAP/UERJ entre 1978 e 1980; professora assistente no Departamento de Psicologia e Orientação Educacional da Faculdade de Educação da UFJF entre 1991 e 1993. É pedagoga, orientadora educacional, do CAP/UFRJ desde 1993.

Ficha catalográfica.

Abreu, Rosane de Albuquerque dos Santos

A Internet na prática docente: novos desafios e conflitos para os educadores / Rosane de Albuquerque dos Santos Abreu; orientadora: Ana Maria Nicolaci-da-Costa - Rio de Janeiro: PUC-Rio, Departamento de Psicologia, 2003.

172 fls.

Tese de Doutorado - Pontifícia Universidade Católica, Departamento de Psicologia.

1. Psicologia - Tese. 2. Internet e prática docente. 3. Conflitos e desafios para os educadores. 4. Conhecimento. 5. Identidade profissional. 6. Mercado de trabalho. I. Abreu, Rosane de Albuquerque dos Santos e. II. Nicolaci-da-Costa, Ana Maria. III. Pontifícia Universidade Católica do Rio de Janeiro. Departamento de Psicologia. IV. Título. 


\section{AGRADECIMENTOS}

À Ana, por ter aceitado embarcar comigo nesta viagem, ajudando-me a manter o rumo e a ultrapassar as tormentas. Com você aprendi uma nova forma de fazer pesquisa, a olhar o novo com curiosidade, sem medos e preconceitos. Obrigada pela atenção, pelo cuidado, pela confiança e, até mesmo, pelos puxões de orelha, pois foram todos para me ajudar a crescer. Mais do que professora e orientadora, você foi amiga.

Aos meus pais Pedro e Dyrce, agradeço a vida e a formação que me deram. Com vocês aprendi a lutar pelos meus ideais e a não esmorecer diante dos obstáculos.

Ao meu marido Luiz Carlos, agradeço pelo incentivo, pela paciência, por aceitar a minha ausência durante este período e pelo respeito que sempre teve ao meu trabalho. Com você aprendi que sempre temos que ir ao encontro de nossos sonhos.

Aos meus filhos Leonardo, Anelise e Andréia, que com sua juventude e uma visão de mundo diferente da minha, me ensinam a "ficar fria" e "não ficar bolada" com as coisas novas que não entendo. A vocês, que são a minha melhor produção, o meu carinho.

Aos meus sogros, irmãos, cunhados e sobrinhos, pelo carinho e incentivo. Aos meus irmãos Ione e Pedro, obrigado por me ajudarem a solucionar os problemas da informática.

À Carla que me ajudou na adaptação ao doutorado e com quem pude contar nos momentos mais críticos deste percurso. Obrigada por sempre me mostrar o outro lado das coisas.

Aos professores entrevistados, pois sem eles este trabalho não seria possível.

Aos colegas que intermediaram meu contato com os sujeitos da pesquisa, o meu agradecimento pela ajuda inestimável.

Aos colegas Raphael, Daniela, Ana Cláudia e Carla, primeiro grupo de pesquisa com o qual convivi, obrigado pela acolhida e pelas trocas valiosas.

Ao grupo mais recente, Ana Paula, Andréa, Camila, Daniela, Erika, Renata, Ricardo e Tereza, obrigado pela rica convivência e pelo intercâmbio de idéias.

Às colegas de equipe do CAp/UFRJ, Gláucia, Heloísa, Maria Cecília e Sandra que, acreditando no meu trabalho, puderam aceitar a minha ausência neste período.

À amiga Maria Cecília, pelas importantes opiniões que deu ao meu trabalho e pela ajuda com o Inglês. 
À amiga Rosangela Moreno, pelo incentivo para o ingresso no doutorado e pela ajuda decisiva para que eu obtivesse a licença para estudos.

Aos colegas do CAP- UFRJ, pela rica convivência e pelas trocas que se constituíram em subsídios para definir o meu objeto de estudos. Agradeço especialmente a Célia, Celina, Letícia, Izabel, Maria Cecília e Rosangela, que contribuíram diretamente para este trabalho.

A Beatriz Helena Magno, que deixou muitas saudades, agradeço o incentivo e a oportunidade de estar no EDAI.

Aos alunos do curso de pós-graduação do EDAI- UERJ, com quem muito aprendi.

Aos colegas da pós-graduação do EDAI, pelas importantes trocas na área da informática educativa.

Ao Fábio Ferrentini, pelos importantes comentários ao meu trabalho.

À Carmen que me ajudou a desatar os vários nós que surgiram durante este percurso, mostrando-me, muitas vezes, o que eu não podia ver.

Aos professores da Pós-graduação, por seus ensinamentos. Relembro a Prof ${ }^{\mathrm{a}}$ Anamaria Coutinho, cujo incentivo me levou a estudar o sociólogo Manuel Castells.

Aos meus colegas de turma, pelas ricas trocas no período inicial do doutorado.

À Marise, Verinha, Dudu e Marcelina, pelo apoio, atenção e cuidado.

A VRAc - PUC/RJ, pelo apoio financeiro.

A Deus, pelas graças recebidas durante o doutorado. 


\section{RESUMO}

Abreu, Rosane de Albuquerque dos Santos; Nicolaci-da-Costa, Ana Maria. A Internet na prática docente: novos desafios e conflitos para os educadores. Rio de Janeiro, 2003. 172p. Tese de Doutorado Departamento de Psicologia, Pontifícia Universidade Católica do Rio de Janeiro

A difusão da Internet resultou em profundas transformações sociais, econômicas e culturais. No que concerne à educação, há fortes pressões para a sua aplicação no cotidiano pedagógico. Neste cenário, o professor emerge como o principal responsável pela introdução das novas tecnologias no ambiente escolar e pelas transformações na prática pedagógica que essas tecnologias tornam necessárias. Este desafio, por sua vez, parece ser uma fonte de conflitos pessoais, tensão e sofrimento para esses profissionais.

Com o objetivo de investigar os problemas pessoais e/ou profissionais que estão enfrentando, foram entrevistados 20 professores do ensino fundamental e médio, que utilizam esta tecnologia com seus alunos. A análise de seus depoimentos revela que, confrontados com as novidades trazidas pela Rede, esses docentes estão re-avaliando sua participação no processo pedagógico em pelo menos três setores, para eles particularmente nevrálgicos. (1) Estão revendo a concepção de conhecimento - aquela da transmissão de verdades estabelecidas que tradicionalmente tem sustentado as práticas pedagógicas. (2) Estão questionando o papel do professor como "dono do saber" na era da informação e tentando reconstruir sua identidade profissional perante uma realidade que subverte as expectativas e hierarquias tradicionais. (3) Estão re-avaliando a estabilidade de seus empregos, com medo de serem substituídos ou excluídos do mercado de trabalho em educação - por máquinas ou por professores mais jovens que dominam sua operação.

Palavras-chaves: Internet, Professores, Educação, Conflitos, Conhecimento, Identidade profissional, Mercado de trabalho 


\begin{abstract}
Abreu, Rosane de Albuquerque dos Santos; Nicolaci-da-Costa, Ana Maria. The Internet in schools: new challengers an conflicts for educators. Rio de Janeiro, 2003. 172p. Tese de Doutorado - Departamento de Psicologia, Pontifícia Universidade Católica do Rio de Janeiro
\end{abstract}

The diffusion of the Internet has resulted in deep social, economic and cultural transformations. In education, there has been growing expectation of its use in daily school activities. In such a context, it is assumed to be the school teacher's responsibility not only to introduce the new technologies in daily pedagogical practices but also to operate the transformations in such practices that these technologies require. Such a challenge, on its turn, seems to be a source of personal conflicts, tension and suffering for these professionals.

Aiming at investigating the personal and/or professional problems they are being faced with, 20 interviews were conducted with elementary and high school teachers that use this technology with their students. Analysis of their discourse reveals that, confronted with the novelties brought about by the Net, these teachers are re-evaluating their own participation in the pedagogical process in at least three areas, which are particularly sensitive for them. (1) They are reviewing the concept of knowledge - that of transmission of established truths - which has traditionally supported pedagogical practices. (2) They are questioning the role of the teacher as "the one who always knows" in the information age and trying to reconstruct their professional identity in the face of a reality that subverts trsditional expectations and hierarchies. (3) They are re-evaluating the stability of their jobs because they are afraid to be replaced, or made unemployable, by machines or younger teachers who know how to operate them.

Keywords: Internet, Teachers, Education, Conflicts, Knowledge, Professional identity, Job requirements 


\section{SUMÁRIO}

\section{Internet e Educação: um panorama da produção acadêmica}

brasileira.

2.1. Trabalhos de cunho reflexivo

2.1.1. Reflexões sobre as transformações educacionais decorrentes da Revolução das Tecnologias da Informação.

2.1.2. Reflexões sobre educação à distância.

2.1.3. Professor, protagonista das mudanças educacionais. 22

2.2. Trabalhos de cunho pragmático 24

2.2.1. A Internet e os alunos 24

2.2.1.1. Aplicações dos recursos da Internet no processo ensinoaprendizagem.

2.2.1.2. Efeitos da Internet na cognição e no processo de aprendizagem. 25

2.2.1.3. Desenvolvimento de tecnologias da Internet com finalidades pedagógicas.

2.2.1.4. Experiências de uso da Internet com os alunos: algumas considerações.

2.2.2. A Internet e os professores

2.2.2.1. As reações dos professores e repercussões na prática docente do uso da Internet na educação

2.2.2.2. Capacitação e formação de professores. 36

2.2.2.3. Material de apoio ao professor. $\quad 40$

2.2.2.4. Experiências com professores para uso de computadores e Internet: algumas considerações.

2.3. Internet e Educação: tecendo considerações a respeito da produção acadêmica brasileira.

2.4. Professores e Internet: comentando uma pesquisa preliminar. $\quad 44$

2.4.1. Resultados encontrados 45

2.4.2. Definindo categorias 48

3. A Revolução em Curso $\quad 51$

3.1- O Mundo Mudou 51

3.2- A Revolução das Tecnologias da Informação de Manuel Castells 53

3.2.1- A Natureza Revolucionária das Tecnologias da Informação $\quad 55$

3.2.2- A Sociedade em Rede 56

3.2.3- A Revolução das Tecnologias da Informação: algumas categorias em mutação 59

3.2. Conhecimento: base produtiva da nova sociedade em rede $\quad 59$

3.2.3.2. Identidade na nova sociedade em rede 61 
3.2.3.3. As transformações do mercado de trabalho na sociedade em rede

3.3 - A Revolução Virtual de Pierre Lévy 67

3.3.1- Virtualização: um processo revolucionário 68

3.3.2- A Nova Sociedade Planetária 70

3.3.3- A Revolução Virtual: algumas categorias em mutação 72

3.3.3.1. A nova relação com o saber 76

3.3.3.2. Cibercultura e identidade: a crise de sentido 76

$\begin{array}{ll}\text { 3.3.3.3. As mudanças no mundo do trabalho } & 77\end{array}$

3.4 - A Revolução Digital de Juan Luis Cebrián 78

3.4.1- Digitalização da informação: um processo revolucionário 79

3.4.2- A Sociedade Global da Informação 81

3.4.3- A Revolução Digital: algumas categorias em mutação 83

3.4.3.1. A Informação e o conhecimento 83

3.4.3.2. Identidades em desordem 86

3.4.3.3. O desemprego, o ócio e o trabalho em excesso: a problemática atual do mercado de trabalho $\quad 87$

3.5- Integrando as Idéias de Castells, Lévy e Cebrián 89

4. Com a palavra, os professores: pesquisa de campo.

$\begin{array}{ll}4.1 \text { Objetivos } & 95\end{array}$

4.2- Procedimentos metodológicos 96

4.2.1-Sujeitos 96

4.2.1.1- Critérios de recrutamento 96

4.2.1.2- Perfil dos sujeitos recrutados. $\quad 97$

4.2.2- Coleta de dados 99

4.2.3- Análise dos dados 101

5- Impactos da Internet na prática docente: apresentação e discussão dos resultados da pesquisa $\quad 102$

5.1. Conhecimento em mutação. 102

5.1.1. Computadores e os conhecimentos 103

5.1.2. Internet e as mutações no conhecimento 105

5.1.2.1. Informação e conhecimento: dois conceitos em revisão 106

5.1.2.2. A superficialidade das informações e a profundidade dos
conhecimentos

5.1.2.3. A relativização no lugar da verdade absoluta 112

5.1.2.4. Permanência e renovação dos conhecimentos 114

5.1.2.5. A confiabilidade das fontes de informação 115

5.1.2.6. A lógica linear e o hipertexto. 117

5.1.2.7. A estrutura disciplinar e a interdisciplinaridade 119

5.1.2.8. Resumindo 119

5.2. Identidade em transformação 122

5.2.1. Pressões e exigências geradas pela difusão da Internet. 122 
5.2.1.1. As pressões mercadológicas 123

5.2.1.2. A inversão na hierarquia do saber 125

5.2.1.3. Novos comportamentos dos alunos 127

5.2.2. Resistência: reação de proteção ou etapa para elaboração do novo? 129

5.2.3. Professores em busca de um novo fazer pedagógico 133

$\begin{array}{ll}\text { 5.2.4. Resumindo } & 137\end{array}$

5.3. O mercado de trabalho em mudança 139

5.3.1. Novas oportunidades ocupacionais geradas pela Internet 139

5.3.2. A Internet e o mercado de trabalho em educação 143

5.3.2.1. Medo da substituição do homem pela máquina 146

$\begin{array}{ll}\text { 5.3.2.2. Medo de ser substituído por alguém mais jovem e mais } & \\ \text { sintonizado com as tecnologias } & 148\end{array}$

$\begin{array}{ll}\text { 5.3.3. Resumindo } & 149\end{array}$

6. Internet: fonte de tensões e conflitos docentes 151

\begin{tabular}{lr} 
7. Referências bibliográficas & 160 \\
\hline
\end{tabular}

8. Anexo: Dados de identificação dos sujeitos 172 
"A contínua transformação das técnicas, dos mercados e do meio econômico leva os coletivos a abandonar seus modos de organização rígidos e hierarquizados, a desenvolver a capacidade de iniciativa e de cooperação ativa de seus membros. Nada disso é possivel, porém, a menos que envolva $e$ mobilize efetivamente a subjetividade dos indivíduos".

Pierre Lévy, A Inteligência Coletiva 